\title{
Neuroblastoma in Patients Over 10 Years Old: A 21-Year Experience at a Single Institution
}

\author{
Casteleti P', Senerchia $\mathrm{AA}^{2 *}$ and Caran $\mathrm{E}^{2}$ \\ ${ }^{1}$ Universidade Federal de São Paulo-UNIFESP, Sao Paulo, \\ Brazil \\ ${ }^{2}$ Instituto de Oncologia Pediatrica- GRAACC/ UNIFESP, \\ Sao Paulo, Brazil \\ *Corresponding author: Senerchia AA, Pediatric \\ Oncology Department, Instituto de Oncologia Pediatrica- \\ GRAACC/ UNIFESP, Sao Paulo, Brazil
}

Received: March 29, 2017; Accepted: April 27, 2017; Published: May 04, 2017

\begin{abstract}
Purpose: To improve knowledge about the course and clinical characteristics of patients, we reviewed our the clinical characteristics and outcome of consecutive patients aged 10 years or more at the time they were diagnosed with neuroblastoma in a single institution for a period of 21 years.

Methods: The records of seven consecutive patients over 10 years old with a newly diagnosed neuroblastoma who were treated at the Instituto de Oncologia Pediatrica-GRAACC/UNIFESP in Sao Paulo from January 1991 to 2012 were reviewed.

Results: From 249 patients with Neuroblastoma, 7 were defined as AYA and included in the study. Recurrent disease occurred in 3 of 7 evaluated patients. Time to relapse ranged from 2.5 to 9.3 years (median, 5.6 years) and the time from recurrence to death ranged from 8 to 19.8 months (median, 13.9 months) in 2 of 3 patients with recurrent disease. Progressive disease was present continuously in four patients who died.

Conclusion: Neuroblastoma is very rarely diagnosed past the age of 10 years and we have highlighted that the incidence is very low, though, AYA present a more indolent disease course with long-term relapses and fatal outcomes.

Keywords: Neuroblastoma; Prognosis; Indolent Course; Adolescent and Young Adult
\end{abstract}

\section{Abbreviations}

AYA: Adolescent and Young Adult; NB: Neuroblastoma; HVA: Homovanillic Acid; MIBG: Meta-Iodo-Benzylguanidine; VMA: Vanillylmandelic Acid

\section{Introduction}

Neuroblastoma (NB) is the most common and most deadly solid tumor that occurs in children outside of the brain [1]. Incidence peaks in infancy and then rapidly declines, with less than $10 \%$ of cases diagnosed in adolescents and adults older than 10 years of age [2].

Due to the rarity of disease in adolescents and adults, few series are reported in literature. These reports suggest that older NB patients have unique biology characterized by an indolent disease course with long-term relapses and fatal outcomes, despite the presence of very few unfavorable biologic markers [3-6]. In childhood NB, a genomic profile is a key requirement for the accurate identification of molecular prognostic markers, especially indicated when the MYCN oncogene is not amplified [7-9].

Recent results from studies of older high-risk NB patients showed an age-dependent pattern in overall response [10]. Franks et al. reported that the course of the disease was highly dependent on stage; the majority of adolescents presented with stage 4 , in comparison with localized disease observed among adults [4].

To improve knowledge about the course and clinical characteristics of this population of patients, we retrospectively reviewed the clinical characteristics and outcome of consecutive patients aged 10 years or more at the time they were diagnosed with neuroblastoma in a single institution for a period of 21 years.

\section{Materials and Methods}

Between January 1991 and 2012, seven consecutive patients over 10 years old with a newly diagnosed neuroblastoma were treated at the Instituto de Oncologia Pediatrica-GRAACC/UNIFESP in Sao Paulo. The diagnosis was based on histological examination of tumor biopsy or resection specimens. Patients with a diagnosis of ganglioneuroma were not included in the present study. The diagnostic imaging methods were: extent of disease was evaluated by computed tomography and/or magnetic resonance on the site of the primary tumor, bilateral bone marrow aspirate and biopsy, iodine-131 Meta-Iodo-Benzylguanidine (MIBG) scan. Laboratory analyses included urinary concentrations of Vanillylmandelic Acid (VMA) and Homovanillic Acid (HVA). The number of MYCN oncogene copies was evaluated on fresh frozen tissue in two cases. The disease was staged using the International Staging System criteria. This study was approved by the Institutional Review Board with waiver of informed consent. The following variables were evaluated: gender, age, time from the onset of symptoms to diagnosis, primary tumor site, and stage of disease, the median follow-up and time to relapse. Categorical data were summarized as absolute and relative frequencies; quantitative data were described as median.

\section{Results}

From January 1991 to January 2012, 249 patients with NB were admitted at our institution. Of these, 242 were children aged up to 10 
Table 1: Clinical characteristics and outcome of patients.

\begin{tabular}{|c|c|c|c|c|c|c|c|c|c|}
\hline \multirow[b]{2}{*}{ Case } & \multirow[b]{2}{*}{ Age (years) } & \multirow[b]{2}{*}{ Gender } & \multirow[b]{2}{*}{ Primary tumor site } & \multirow[b]{2}{*}{ Metastases } & \multicolumn{5}{|c|}{ Recurrence } \\
\hline & & & & & Disease stage & $\mathrm{Y} / \mathrm{N}$ & $\begin{array}{l}\text { Time in years } \\
\text { from diagnosis }\end{array}$ & Outcome & $\begin{array}{c}\text { Survival } \\
\text { (years) }\end{array}$ \\
\hline 1 & 11.5 & M & Not know & $\mathrm{Y}$ & IV & $\mathrm{N}$ & NA & DOD & 2.06 \\
\hline 2 & 10.8 & M & Right adrenal & $\mathrm{Y}$ & IV & $\mathrm{Y}$ & 5,6 & Alive & 11.37 \\
\hline 3 & 16.6 & $\mathrm{~F}$ & Paravertebral & $\mathrm{N}$ & III & $\mathrm{Y}$ & 2,5 & DOD & 4.15 \\
\hline 5 & 10.9 & $\mathrm{~F}$ & Paravertebral & $\mathrm{Y}$ & IV & $\mathrm{N}$ & NA & DOD & 2.88 \\
\hline 6 & 30.1 & M & Paravertebral & Y & IV & $\mathrm{N}$ & NA & DOD & 3.32 \\
\hline 7 & 10.4 & $\mathrm{~F}$ & Left adrenal & $\mathrm{Y}$ & IV & $\mathrm{Y}$ & 9,3 & DOD & 10.01 \\
\hline
\end{tabular}

Y-yes; N-no; NA-not applicable; DOD-dead of disease.

years and 7 were defined as adolescent and young adult (AYA) and included in the study. Clinical characteristics and outcome of patients are presented in Table 1 .

In this series of 7 patients with NB, 4 were females, and the median age was 11.5 years (range, 10.4-30.1). The primary site of the tumor was the had a longer time interval instead of had a length interval in 3 patients, the adrenal in 3 ; in one case the site of the primary tumor was not know. As for stage, 6 cases were stage 4 and one was stage 3 . The main sites of distant metastasis were bone marrow $(n=4)$, lymph nodes $(n=4)$ and bone $(n=2)$. MYCN status was assessed in 2 patients and was amplified in one. The mean time from symptom onset to diagnosis was 6 months (range, 1-24) in 6 patients. This information was unknown for one patient. In most of the cases, the presenting sign and symptoms included bone pain (4), abdominal mass (3), fever (2), loss of weight (2), abdominal pain (1) and neurological alteration (1). Recurrent disease occurred in 3 of 7 evaluated patients. Time to relapse ranged from 2.5 to 9.3 years (median, 5.6 years) and the time from recurrence to death ranged from 8 to 19.8 months (median, 13.9 months) in 2 of 3 patients with recurrent disease. Progressive disease was present continuously in four patients who died. The median follow-up was 3.3 years (range, 2.06 - 11.4). By the time of the last follow-up, only one patient (14\%) was alive after a median follow-up of 11.37 years.

\section{Discussion}

Like the AYA patients in previous studies, the subgroup of AYA with NB in the current study represents less than $5 \%$ of patients with childhood NB.

An important consideration is the manner in which age has been converted to a categorical variable. Some authors have evaluated children as the person who has not yet completed twelve years of age [5,11], while others have defined children as all under ten years of age $[3,6,12,13]$ and still others have used a cut-off set at 13 year old [4]. We considered adolescent according the definition of the World Health Organization, that considered an adolescent as any person between ages 10 and 19 .

In this series, the most frequent site of the primary tumor was adrenal and paravertebral instead of par vertebral. The signs and symptoms at presentation in the older patients were much the same as the reported in the children under 10 years old $[3,6,13]$

However the adolescents and young adults had a longer time interval instead of had a length interval between the appearance of the first symptom and the diagnosis, probably due the rarity of $\mathrm{NB}$ in AYA and a different NB growth pattern between children and older subjects. The stage found were also similar to those found in young children, most patients presenting with stage IV disease [3$5,11,13]$. These observations are similar to those reported in previous adolescent and adult series, with the majority of patients with stage IV disease with bone marrow involvement $[3,13]$.

Recent studies have suggested NB in adolescents is a special subgroup characterized by high-risk prognostic features which differ from those seen in younger patients, especially in relation to genetic abnormalities [13]. Although these patients may have a more indolent course and infrequent MYCN amplification $[4,5,14]$, older children with advanced disease have a poor rate of survival.

\section{Conclusion}

The current study is limited by its retrospective, single institution nature. However, NB is very rarely diagnosed past the age of 10 years and we have highlighted that the incidence is very low, though, AYA present a more indolent disease course with long-term relapses and fatal outcomes. NB should be considered in the differential diagnosis of the tumors originating in the sites where sympathetic nervous system tissue is present.

\section{References}

1. Maris JM, Hogarty MD, Bagatell R, Cohn SL. Neuroblastoma. Lancet. 2007; 369: 2106-2120.

2. Esiashvili N, Goodman M, Ward K, Marcus RB, Johnstone PA. Neuroblastoma in adults: Incidence and survival analysis based on SEER data. Pediatr Blood Cancer. 2007; 49: 41-46.

3. Conte M, Parodi S, De Bernardi B, Milanaccio C, Mazzocco K, Angelini P, et al. Neuroblastoma in adolescents: the Italian experience. Cancer. 2006; 106: 1409-1417.

4. Franks LM, Bollen A, Seeger RC, Stram DO, Matthay KK. Neuroblastoma in adults and adolescents: an indolent course with poor survival. Cancer. 1997; 79: 2028-2035.

5. Kushner BH, Kramer K, LaQuaglia MP, Modak S, Cheung NK. Neuroblastoma in adolescents and adults: the Memorial Sloan-Kettering experience. Med Pediatr Oncol. 2003; 41: 508-515.

6. Gaspar N, Hartmann O, Munzer C, Bergeron C, Millot F, Cousin-Lafay L, et al. Neuroblastoma in adolescents. Cancer. 2003; 98: 349-355.

7. Schleiermacher G, Michon J, Ribeiro A, Pierron G, Mosseri V, Rubie H, et al. Segmental chromosomal alterations lead to a higher risk of relapse in infants with MYCN-non-amplified localised unrespectable/disseminated 
neuroblastoma (a SIOPEN collaborative study). $\mathrm{Br}$ J Cancer. 2011; 105 1940-1948.

8. Carén $\mathrm{H}$, Kryh $\mathrm{H}$, Nethander $\mathrm{M}$, Sjöberg RM, Träger $\mathrm{C}$, Nilsson $\mathrm{S}$, et al High-risk neuroblastoma tumors with 11q-deletion display a poor prognostic, chromosome instability phenotype with later onset. Proc Natl Acad Sci USA. 2010; 107: 4323-4328

9. Tomioka N, Oba S, Ohira M, Misra A, Fridlyand J, Ishii S, et al. Novel risk stratification of patients with neuroblastoma by genomic signature, which is independent of molecular signature. Oncogene. 2008; 27: 441-449.

10. Polishchuk AL, Dubois SG, Haas-Kogan D, Hawkins R, Matthay KK Response, survival, and toxicity after iodine-131-metaiodobenzylguanidine therapy for neuroblastoma in preadolescents, adolescents, and adults. Cancer. 2011; 117: 4286-4293.

11. Podda MG, Luksch R, Polastri D, Gandola L, Piva L, Collini P, et al.
Neuroblastoma in patients over 12 years old: a 20-year experience at the Istituto Nazionale Tumori of Milan. Tumori. 2010; 96: 684-689.

12. Mossé YP, Deyell RJ, Berthold F, Nagakawara A, Ambros PF, Monclair T, et al. Neuroblastoma in older children, adolescents and young adults: a report from the International Neuroblastoma Risk Group project. Pediatr Blood Cancer. 2014; 61: 627-635

13. Castel V, Villamón E, Cañete A, Navarro S, Ruiz A, Melero C, et al. Neuroblastoma in adolescents: genetic and clinical characterisation. Clin Transl Oncol. 2010; 12: 49-54.

14. Mazzocco K, Defferrari R, Sementa AR, Garaventa A, Longo L, De Mariano $M$, et al. Genetic abnormalities in adolescents and young adults with neuroblastoma: A report from the Italian Neuroblastoma group. Pediatr Blood Cancer. 2015; 62: 1725-1732.
Austin Pediatr - Volume 4 Issue 1 - 2017

ISSN : 2381-8999 | www.austinpublishinggroup.com

Senerchia et al. (C) All rights are reserved
Citation: Casteleti P, Senerchia AA and Caran E. Neuroblastoma in Patients Over 10 Years Old: A 21-Year Experience at a Single Institution. Austin Pediatr. 2017; 4(1): 1052. 